\title{
PENGEMBANGAN KOMPETENSI GURU SEKOLAH LUAR BIASA DALAM ASESMEN POTENSI DAN KOMUNIKASI KEDUKAAN
}

\author{
Fathul Lubabin Nuqul, Yulia Sholichatun, Ardana Reswari Miranda Ningrum \\ UIN Maulana Malik Ibrahim Malang \\ Lubabin_nuqul@uin-malang.ac.id, sholihah.y@gmail.com,nareswariarda@gmail.com
}

\section{Info Artikel}

\section{Riwayat Artikel:}

Diterima: Desember 2019

Direvisi: Maret 2020

Diterbitkan: September 2020

\section{Keywords:}

Children with Special Needs

Grief Communication

Multiple Intelligence

Assessment

\begin{abstract}
The state pays more attention to children with special needs. Through the Indonesian Minister of Education Regulation No. 70/2009, students who have physical, emotional, mental, social disabilities and / or have the potential for intelligence and / or special talents need to get educational services that are in accordance with their needs and human rights. This regulation responds to the increasing number of children with special needs in this country. School management continues to be burdened in relation to providing good service in teaching children with special needs. But on the other hand, the stigma of society about children with special needs makes the teaching and learning process for children with special needs less optimal. The community, especially parents, do not understand that children with special needs also have advantages that can be put forward. Teachers, on the other hand, have a central role in seeing potential and communicating to families of children with special needs. For this reason, this activity aims to provide reinforcement for teachers to carry out assessment and communication to children with special needs. This activity was carried out at Putra Jaya Lowokwaru Malang Special School. The results show that multiple intelligence based assessment of disability and potential is urgently needed. In addition, teachers also need grief communication skills. This activity has provided the teacher with knowledge about what is needed. This activity also requires more intense training and practice.
\end{abstract}

Copyright $(2020$ JRCE. All rights reserved.

\section{Korespondensi:}

Fathul Lubabin Nuqul, UIN Maulana Malik Ibrahim Malang,

Jl. Gajayana No. 50 Malang, Jawa Timur, Indonesia 65144

Lubabin_nuqul@uin-malang.ac.id

\section{PENDAHULUAN}

Pada tahun 2009, Menteri Pendidikan mengeluarkan peraturan menteri pendidikan nasional republik Indonesia nomor 70 yang menyebutkan bahwa peserta didik yang memiliki memiliki kelainan fisik, emosional, mental, sosial, dan/atau memiliki potensi kecerdasan dan/atau bakat istimewa perlu mendapatkan layanan pendidikan yang sesuai dengan kebutuhan dan hak asasinya [1]. Peraturan ini menegaskan bahwa seluruh anak Indonesia memiliki hak terhadap akses pendidikan terlepas dari kondisi individu. Meskipun peraturan telah menjamin hak seluruh anak terhadap pendidikan, termasuk anak berkebutuhan khusus (ABK), namun 
menyelenggarakan pendidikan yang sesuai bagi ABK bukan hal yang mudah. ABK memiliki kondisi khusus yang tidak sama dengan anak tanpa disabilitas maupun ABK lainnya. Hal tersebut menjadikan spesialisasi pendidikan anak ABK perlu mendetil direncanakan dan dilaksanakan agar peserta didik ABK dapat berkembang.

Pada tahun 2016, terdapat 1.962 sekolah luar biasa (SLB) negeri maupun swasta yang tersebar di seluruh Indonesia. Tercatat bahwa setiap harinya 114.085 siswa belajar di semua sekolah luar biasa tersebut [2]. Jumlah tersebut merupakan representasi dari urgensi pengembangan pendidikan SLB secara kontinu agar dapat memfasilitasi ratusan ribu anak negeri yang berstatus ABK untuk melepas streotype bahwa ABK merupakan anak yang tidak berdaya. Pendidikan Nasional bertujuan mencerdaskan kehidupan bangsa dan mengembangkan manusia Indonesia seutuhnya, yakni manusia yang beriman dan bertaqwa terhadap Tuhan Yang Maha Esa dan berbudi pekerti luhur, memiliki pengetahuan dan ketrampilan, kesehatan jasmani dan rokhani, kepribadian yang mantap dan mandiri serta rasa tanggung jawab kemasyarakatan dan kebangsaan.

Anak ABK memiliki potensi yang sama untuk menjadi insan yang dicita-citakan pendidikan nasional dengan bantuan khusus. Namun potensi tersebut masih jarang dikenali karena fokus pendidikan SLB pada handicap yang dimiliki oleh peserta didik. Padahal idealnya, pendidikan khusus untuk anak ABK tidak cukup didasarkan pada kebutuhan atau keterbatasan anak, namun juga bakat anak.

Dalam membahas bakat anak ABK, konsep kecerdasan jamak atau multiple intelligence dapat menjadi konsep yang baik. Rile, Jade, Opulencia, Decenorio, dan Tan (2015) siswa dengan ketidakmampuan belajar memiliki kemampuan khusus yang tidak muncul dalam sistem pendidikan tradisional. Konsep multiple intelligences dapat membantu anak menampilkan kekuatan dan minat mereka. Multiple intelligences dapat memberi implikasi luas untuk pendidikan khusus. Konsep multiple intelligence memiliki spektrum kemampuan yang luas, sehingga membantu memaknai "kebutuhan khusus" anak dalam konteks yang lebih luas. Pendidik yang melihat kebutuhan khusus anak dalam konteks delapan kecerdasan dapat memandang semua siswa berbeda dan dapat bertumbuh pada jenis kecerdasan yang paling menonjol.

Selain itu, penerapan asesmen multiple intelligence pada kasus anak ABK juga memberikan pemaham baru. Penelitian Al-onizat (2016) mengungkapkan bahwa pada anak-anak dengan disabilitas ringan mampu menunjukkan performa yang tinggi di semua tipe kecerdasan jamak Gardner. Kecerdasan jamak pada anakanak tersebut juga diketahui tidak dipengaruhi gender maupun jenis instansi pembelajaran. Ini memberi harapan bahwa disabilitas tidak menghambat pertumbuhan potensi anak-anak. Selanjutnya Al-onizat juga mengungkapkan bahwa jenis disabilitas yang dimiliki anak biasanya dapat memberikan kondisi yang khas bagi kecerdasan jenis tertentu untuk berkembang dengan baik. Anak dengan disabilitas mental nampak menonjol pada kecerdasan musik. Sedangkan anak autis memiliki kecerdasan kinestetik yang lebih menonjol dan bidang aritmatika dibandingkan anak dengan disabilitas mental. Hussen (2010) juga menemukan manfaat program pendidikan yang menggunakan kegiatan kecerdasan majemuk terbukti berdampak efektif pada anak-anak disabilitas mental. Anak-anak ABK yang belajar keterampilan dasar karate dengan pendekatan kecerdasan jamak menunjukkan kemampuan yang baik serta mengalami peningkatan pada beberapa aspek psikologis dan sosial. Senada dengan Al-onizat, Takahashi (2013) juga mengusulkan penerapan teori kecerdasan jamak untuk pendidikan inklusif berdasarkan pertimbangan terhadap berbagai profil kecerdasan yang ditunjukkan oleh anak-anak dengan disabilitas intelektual dan gangguan perkembangan. Pertimbangan ini dipandang dapat meningkatkan program pelatihan guru untuk menyediakan pendidikan yang memadai atau teknik penilaian yang tepat pada anak-anak ABK.

Pengenalan terhadap kecerdasan jamak yang dimiliki anak ABK, tidak hanya akan membantu pendidik dalam menyusun metode pembelajaran anak ABK yang sesuai, namun juga akan membantu orangtua anak ABK untuk mengenali kekuatan anak. Dengan mengenali kekuatan anak, orangtua dapat membentuk persepsi baik dan meningkatkan harapan terhadap perkembangan anak. Persepsi yang baik dan harapan penting dalam memberikan pengasuhan yang positif terhadap anak ABK. Stres dan koping pada orang tua dari anakanak dengan disabilitas intelektual bertumpu pada penilaian kognitif orangtua. Penilaian kognitif tersebut mempengaruhi tingkat stres dan adaptasi orang tua terhadap kesulitan yang dihadirkan oleh anak-anak [7]. Persepsi yang baik akan memberi efek yang positif pada penilaian kognitif orangtua sehingga secara tidak langsung dapat membantu orangtua dalam mengatasi stres dan kesulitan beradaptasi.

Anak ABK membutuhkan dukungan dan integrasi dari sekolah maupun keluarga untuk dapat berkembang. Namun keluarga dengan anak ABK menghadapi berbagai kesulitan dalam memberi dukungan terhadap anak. Kesulitan tersebut dapat besifat materil maupun non materil. Raya, Ruiz-olivares, Pino, dan Herruzo (2013) menyoroti bahwa orangtua dengan anak ABK memiliki level adaptasi yang lebih rendah dibandingkan orangtua dengan anak non ABK. Padahal adaptasi orangtua dapat mempegaruhi interaksi di dalam keluarga dan integrasi pengasuhan. Kendala adaptasi yang dihadapi orangtua dengan anak ABK disebabkan karena orangtua mengalami masa berduka ketika mengetahui bahwa anak mereka teridentifikasi ABK. 
Kandel dan Merrick (2003) mengungkapkan ketika anak dilahirkan dengan disabilitas, keluarga akan mengalami kesulitan dalam beradaptasi. Selain itu keluarga perlu mengatasi stres, kesedihan, kekecewaan, dan tantangan, yang dapat mengarah pada krisis serius atau bahkan gangguan kehidupan keluarga. Orang tua harus mengoordinasikan penilaian, evaluasi, dan berbagai perawatan sambil mempertahankan kontak dengan banyak profesional dan berbagai institusi atau layanan demi anak.

Kesulitan-kesulitan yang dialami orangtua diperburuk dengan keterbatasan dukungan sosial yang tersedia. Bahkan tekanan sosial terhadap orangtua dengan anak ABK cenderung lebih tinggi dibandingkan dukungan sosial yang didapatkan. Mayoritas keluarga dengan anak-anak disabilitas mengalami kesulitan yang mirip. Para ibu menanggung hampir seluruh tanggung jawab pengasuhan, namun tidak menerima dukungan yang memadai. Dua dari lima ibu disalahkan oleh anggota keluarga karena memiliki anak disabilitas, dan hampir setengah dari keseluruhan kasus, yang menyalahkan ibu adalah keluarga dari suami. Lebih dari 50\% ibu mengalami kesedihan yang mendalam dan perasaan kewalahan, dan dua pertiga mengalami kemarahan. Para ibu menyatakan bahwa mereka tidak menerima dukungan emosional yang memadai. Padahal kehidupan sosial, kehidupan kerja, dan hubungan keluarga mereka terpengaruh karena hadirnya anak dengan kondisi khusus. Mayoritas keluarga menginginkan dukungan, informasi dan konseling tentang kondisi anak dari ahli dan ingin menerima dukungan untuk perawatan di rumah dan dukungan psikologis untuk diri mereka sendiri [10].

Dukungan pihak lain, khususnya pihak sekolah, dapat membantu orangtua dalam menghadapi serangkaian krisis dan masalah tersebut. Komunikasi pendidik terhadap keterbatasan dan kekuatan kecerdasan jamak yang dimiliki anak dapat membantu orangtua melihat sisi positif dari situasi sulit mengasuh anak ABK. Dengan membantu orangtua untuk dapat beradaptasi, secara tidak langsung, sekolah juga mencegah hambatan dalam perkembangan dan belajar lainnya yang dapat dialami peserta didik oleh pengasuhan yang negatif.

Berdasarkan latar belakang pengabdian, maka pengabdian uin mengabdi dengan tema pengembangan kompetensi guru sekolah luar biasa dalam asesmen potensi dan komunikasi kedukaan di slb putra jaya kota malang bertujuan untuk mengetahui kebutuhan kompetensi guru slb; pola-pola asesmen yang digunakan oleh guru untuk mengidentifikasi potensi abk; memberikan penguatan dalam asesmen potnesi serta komunikasi kedukaan pada orang tua abk.

Kegiatan ini di dorong adanya peningkatan angka anak berkebutuhan khusus (ABK) berimplikasi pada kebutuhan akan perhatian lebih dalam sistem pengajaran dan penanganan siswa ABK. Kondisi yang umum terjadi pada kelas-kelas di SLB dengan keberadaan siswa yang beragam membuat guru kesulitan melakukan standar keberhasilan belajar siswa, di samping juga menemukan sisi keberbakatan anak secara tepat. Keberbakatan mempunyai dua fungsi dalam penanganan ABK, yakni memberikan arah pembinaan vokasi siswa dan memberikan citra positif ABK pada orang tua. Oleh karena itu program ini lebih menitikfokuskan pada asesmen potensi keberbakatan ABK dan komunikasinya pada orangtua. Diharapkan program ini akan memberikan manfaat berupa: 1) memperkaya perbendaharaan instrumen asesmen yang berorientasi pada sisi positif ABK yang harus dididik di kelas, sehingga guru tidak terfokus hanya pada handicap ABK semata, tapi juga mempunyai perhatian pada potensi yang dikembangkan; dan 2) memberikan manfaat pada guru agar dapat mengkomunikasikan hasil asesmen pada orang tua secara baik. Orang tua yang kurang tepat memperlakukan ABK disebabkan karena merasa bahwa ABK ada stigma bagi keluarga. Untuk itu guru harus memberikan pemahaman pada orang tua tentang potensi ABK dengan menghadirkan bukti-bukti empiris.

\section{METODE PENELITIAN}

Dalam kegiatan kali ini menggunakan metode Partipatory action research (PAR). Pendekatan ini merupakan pendekatan riset di masyarakat dengan metitik beratkan pada patisipasi stake holder dan tindakan. PAR berusaha memahami lapangan dengan berusaha melakukan perubahan dengan berkolaborasi dan melakukan tindakan reflektif.

Pada kegiatan ini dilakukan dengan berbagai tahap. Pertama, Sebelum melaksanakan kegiatan utama untuk memenuhi kondisi yang diharapkan, dilakukan need assesment melalui diskusi bersama kepala sekolah dan guru-guru SLB Putra Jaya. Proses need assesment dilakukan dalam dua kali pertemuan,

Pertemua awal dengan kepala sekolah dengan menggunakan wawancara mendalam para tanggal 6 Oktober 2019. Dalam wawancara ini menghasilkn beberapa poin seperti sejarah SLB Putra Jaya, perkebambangan siswa dan sistem pembelajaran yang dilakukan secara umum selain menyepakati kegaiatan yang akan dilakukan. Pertemuan selanjutnya FGD dengan guru-guru yang dilaksanakan pada tanggal 11 Oktober 2019. Pertemuan ini menghasilkan simpulan dua masalah penting yang ingin diselesaikan oleh kepala sekolah dan guru-guru SLB Putra Jaya. Dua masalah tersebut adalah kendala asesmen terhadap siswa dan kendala komunikasi dengan orangtua yang memiliki sikap kurang positif terhadap perkembangan anak.

Kedua Tahap selanjutnya adalah penyusunan bentuk kegiatan yang tepat untuk mencapai penyelesaian dari masalah yang ditetapkan. Kegiatan sosialisasi dipilih sebagai intervensi karena dapat memadai untuk 
menjadi sarana transfer ilmu dan keterampilan yang dibutuhkan oleh guru. Kegiatan pelatihan diselenggarakan pada tanggal 8 November 2019 pukul 13.00 dengan susunan acara sebagai berikut:

Tabel 1: Kegiatan Sosialisasi pada Guru SLB Putra Jaya

\begin{tabular}{|l|l|l|l|}
\hline NO & Materi & Narasumber & Gambaran Kegiatan \\
\hline 1 & Sambutan & Babil Abuyajit, S.Pd, M.Pd & $\begin{array}{l}\text { Dalam sambutan disampaikan } \\
\text { tujuan dari kegiatan kali ini yaitu } \\
\text { untuk melakukan asesmen dan } \\
\text { komunikasi pada orang tua }\end{array}$ \\
\hline 2 & $\begin{array}{l}\text { Asesemen Instrumen } \\
\text { Multiple Intelligences } \\
\text { bagi anak ABK }\end{array}$ & $\begin{array}{l}\text { Dr. Fathul Lubabin Nuqul, } \\
\text { M.Si, Psikolog }\end{array}$ & $\begin{array}{l}\text { pada sesi ini dilakukan } \\
\text { pengenalan asesmen multiple } \\
\text { inteligent untuk ABK dan sistem } \\
\text { sistem asesmen berbasis online } \\
\text { dengan aplikasi http://app.siabk- } \\
\text { semar.com }\end{array}$ \\
\hline 3 & $\begin{array}{l}\text { Peran Sekolah dalam } \\
\text { Meningkatkan } \\
\text { Penerimaan Orangtua } \\
\text { terhadap Disabilitas } \\
\text { Anak }\end{array}$ & $\begin{array}{l}\text { Dr. Yulia Solichatun, M.Si. } \\
\text { Psikolog }\end{array}$ & $\begin{array}{l}\text { Pada sesi ini peserta diajak } \\
\text { berdiskusi tentang cara-cara } \\
\text { melakukan komunikasi dengan } \\
\text { orang tua }\end{array}$ \\
\hline 4 & Penutup & Tim & \\
\hline
\end{tabular}

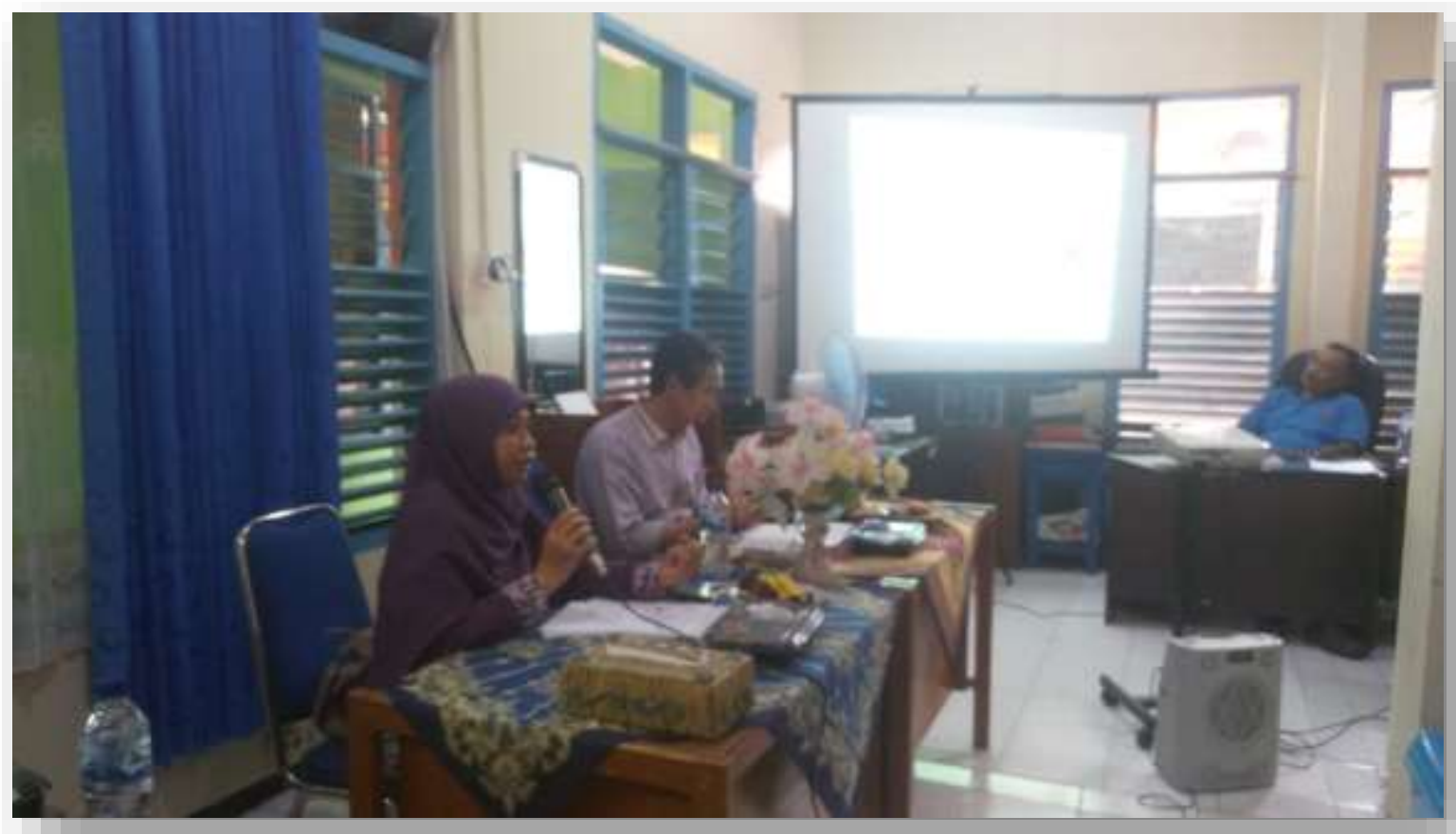

Gambar 1

Salah satu sesi materi Komunikasi kedukaan

Tahap terakhir adalah evaluasi. Evaluasi dilakukan terhadap kegiatan yang telah dilakukan sebagai penilaian efektifitas kegiatan untuk mencapai kondisi yang diharapkan. Pada sesi refleksi ini peserta menginginkna adanya tindak lanjut untuk tetap berkomunikasi dengan pada tim peneliti. Beberapa hal yang diharapkan dalam sesi ini adalah adanya pelatihan konseling bagi guru secara lebih mendalam sehingga akan memberikan penguatan kompetensi guru dalma melakukan konseling. Revisi beberapa item dalam instrumen Multiple inteligent agar lebih sesuai dengan kondisi dan kebutuhan siswa ABK.

\section{Subjek Dampingan}

Sekolah Luar Biasa (SLB) Putra Jaya Kota Malang merupakan salah satu lembaga pendidikan khusus yang berdiri sejak 2 Mei Tahun 1973. SLB Putra Jaya memiliki 80 siswa ABK dengan jenis kekhususan yang didominasi oleh tunagrahita ringan, tunagrahita sedang, dan sebagian siswa lain yang dengan ketunaan lain. Berikut data keadaan siswa pada awal tahun pelajaran 2019/2020. 
Untuk menyediakan layanan pendidikan terhadap siswa ABK, terdapat 20 tenaga pendidik dan 8 tenaga kependidikan yang setiap hari membantu siswa berkembang di sekolah. Berikut ini merupakan data tenaga edukatif dan non edukatif di SLB Putra Jaya:. SLB Putra Jaya Terletak di JL Nusa Indah Jati Mulya No 11 Lowokwaru.

\section{HASIL DAN PEMBAHASAN}

Menerapkan multiple intellegences pada pendidikan khusus bagi anak ABK memang terdengar menjanjikan. Namun berdasarkan proses review yang dilakukan bersama guru dan kepala sekolah SLB Putra Jaya, disadari bahwa instrumen multiple intelligences masih perlu pembenahan untuk dapat sesuai dengan berbagai jenis ketunaan yang disandang oleh peserta didik. Beberapa disabilitas yang melibatkan keterbatasan fisik dapat berakibat pada kemustahilan salah satu jenis kecerdasan berkembang, seperti peserta didik yang menyandang tuna netra secara alami tidak dapat mengembangkan kecerdasan motorik yang baik. Hal ini berimplikasi pada kelayakan instrumen multiple intelligences yang digunakan untuk diterapkan pada asesmen anak ABK. Keengganan anak dalam berkegiatan dan kurang koperatifnya orangtua terhadap kegiatan pembelajaran di sekolah menjadi masalah yang sering muncul berdasarkan sesi diskusi dalam sosialisasi yang dilakukan. Penerapan multiple intelligences dan membangun komunikasi positif dengan orangtua dapat menjadi solusi terhadap masalah ini. Melalui mengenali jenis kecerdasan majemuk yang dimiliki anak ABK, pendidik tidak hanya dapat mengenali kelebihan anak, namun juga mengenali bidang atau kegiatan yang menjadi kegemaran anak. Melakukan kegiatan yang digemari dan dikuasai anak akan membuat anak bersemangat dan membangun kepercayaan diri anak. Kecerdasan majemuk yang dimiliki anak dapat menjadi umpan diskusi yang menarik dan menumbuhkan harapan bagi orangtua dengan sikap kurang koperatif. Membicarakan sisi positif anak yang ditemukan lewat asesmen multiple intelligences juga dapat membantu orangtua mengatasi keberdukaan yang dirasakan.

Instrumen asesmen anak ABK berbasis multiple intelligences direview secara positif oleh guru secara fungsi namun memerlukan pembenahan pada item-item untuk dapat lebih sesuai dengan kondisi disabilitas anak $\mathrm{ABK}$ yang beragam. Instrumen multiple intelligences membawa perspektif positif yang luput oleh guru dan orangtua mengenai kelebihan anak ABK. Handicap yang dimiliki anak selalu jadi fokus perhatian sehingga kelebihan anak terabai untuk dikembangkan. Dengan mengenali jenis kecerdasan majemuk anak, orangtua dan guru dapat lebih baik dalam merancang pembelajaran khusus untuk mengembangkan kelebihan anak ABK. Selain itu alternatif dalam kegiatan pembelajaran juga dapat semakin variatif dengan mengenali bidang keberbakatan anakyang menjadi kegemaran dan keahlian.

Gadner mengatakan bahwa hakekatnya manusia mempuyai kecerdasan jamak (multiple intelligences). Teori Gadner ini mengimplikasikan bahwa seorang individu yang kurang mampu dalam satu bidang, masih berpeluang mempunyai potensi di bidang yang lain. konsep ini juga berlaku untuk ABK. Misalnya anak tuna netra tidak mampu melihat, tetap mampu mengoptimalkan indra kinertetik dan somestasinya. Sesuai dengan konsep multiple intelligences seorang guru mampu mengidentifikasi kekuatan atau potensi istimewa ABK melalui instrumen yang terstandar

\section{Komunikasi keberdukaan}

Orangtua yang kurang koperatif terhadap pembelajaran anak di sekolah biasanya tidak disiplin dalam pendidikan anak. Orangtua cenderung membiarkan anak tidak sekolah dalam waktu yang lama karena kesulitan psikis maupun materil yang dialami. Alih-alih mencari bantuan dengan berdiskusi bersama guru, orangtua biasanya lebih memilih menghilang begitu saja. Tidak ada konfirmasi mengenai ketidakhadiran anak di sekolah dan alasan yang menyebabkannya. Untuk mengatasi hal ini, guru biasanya melakukan home visit. Namun home visit yang dilakukan guru belum diperkuat dengan keterampilan komunikasi atau konseling sehingga guru pun merasa kebingungan untuk mengajak orangtua dan anak kembali ke sekolah. Oleh karena itu pemahaman terhadap siklus keberdukaan orangtua perlu menjadi dasar komunikasi agar guru dapat membantu orangtua mampu menyampaikan masalah yang menghalangi pengasuhan dan pendidikan optimal terhadap anak. Orangtua yang tidak dapat mengatasi penderitaan batinnya tidak dapat memberikan pengasuhan yang sehat dan baik bagi buah hatinya yang mengalami disabilitas.

Ray, Pewitt-Kinder, dan George (2009) menyarankan bahwa penting untuk mengklasifikasikan keluarga berdasarkan tahapan penyesuaian terhadap ketidakmampuan anak, juga memahami bahwa keluarga memiliki beragam reaksi dan dapat mengatasi perasaan mereka dengan cara dan langkah yang berbeda. Sangat membantu untuk menyadari bahwa pendidik perlu memberi perhatian dan memahami orangtua yang tidak koperatif dengan sikap yang positif. Mendengarkan keluarga adalah kunci dalam bekerjasama dengan orangtua sebagai mitra dalam mendukung pembelajaran dan pengembangan anak ABK. Lebih lanjut, pendampingan terhadap orangtua dapat dilaksanakan dengan mendorong orangtua melalui tahapan-tahapan berikut: Pertama, Fase burung unta. Orang tua tidak menyangkal anak mengalami disabilitas tetapi tidak sepenuhnya menyadari dampaknya. Misalnya, orang tua mungkin berkata, "Anak saya seperti anak laki-laki biasa. Dia hanya tidak ingin duduk diam dan membaca buku".Kedua Penunjukan khusus. Orang tua mulai menyadari bahwa anak 
mereka memiliki kebutuhan khusus dan mencari bantuan atau meminta layanan khusus.Ketiga, Normalisasi. Orang tua berusaha membuat perbedaan antara anak mereka dan anak-anak tanpa disabilitas menjadi kurang jelas. Di tahap ini orangtua sudah pada keadaan mental yang lebih baik dan dapat memberi pengasuhan yang lebih kondusif pada anak. Keempat Aktualisasi diri. Orang tua tidak memandang perbedaan anak sebagai lebih baik atau lebih buruk, hanya berbeda. Mereka mendukung anak mereka dalam belajar tentang kecacatannya, termasuk bagaimana menjadi advokat mandiri.

Teori berduka diharapkan berujung pada penerimaan. Teori berduka membantu dalam memahami respons orangtua terhadap pembelajaran bahwa orangtua membutuhkan waktu untuk menyadari anak mereka membutuhkan layanan pendidikan khusus [16]. Namun ternyata dasar pemikiran bahwa kedukaan tersebut berlangsung dalam suatu urutan tertentu adalah tidak benar. Penolakan, kecemasan, ketakutan, rasa bersalah, depresi, dan kemarahan adalah reaksi umum yang timbul namun tidak berarti dirasakan keseluruhan secara berurutan pada setiap orangtua dengan anak ABK. Meskipun keadaan perasaan berduka tidak memiliki urutan, ada pola yang dapat dideteksi. Penyangkalan selalu menjadi yang pertama, tetapi mungkin muncul kembali berulang kali, sesering yang dibutuhkan orang tua untuk mengalaminya. Kecemasan umumnya terjadi setelah penyangkalan, tetapi juga bisa mengikuti perasaan lainnya. Tidak jarang dua atau lebih kondisi perasaan dialami pada saat yang sama. Singkatnya, setiap orang yang melalui proses berduka mengalami masing-masing perasaan, tetapi melakukannya dengan cara dan urutan tersendiri yang unik [13].

Moses melanjutkan, bahwa dalam melewati proses berduka, orangtua membutuhkan bantuan dan dukungan yang besar. Tanpa bantuan dan dukungan, terlebih bila diperburuk dengan tekanan, orangtua dapat menolak proses berduka yang menjadikan orangtua tersebut menjadi memilih menahan perasaan, menyalahkan diri sendiri atau orang lain, merasa getir, tergantung, atau bahkan canggung dalam interaksi mereka. Implikasi lebih jauh dapat membuat orangtua melakukan koping non adaptif seperti menjadi pecandu kerja, menutup diri, dan lain sebagainya. Perilaku atau kebiasan hidup yang memburuk menunjukkan kebuntuan orangtua dalam menanggapi keberdukaan. Inilah orangtua yang tidak bisa atau tidak mau mengalami perasaan berduka. Hal ini dapat terjadi karena dukungan yang minim serta orang sekitar yang tidak menunjukkan penerimaan terhadap rasa duka yang dialami orangtua tersebut. Setiap perasaan, meskipun negatif, memiliki fungsi spesifik dan bermanfaat. Untuk melepaskan impian terhadap seorang anak yang ideal, seseorang harus mengalami dan berbagi penolakan, kecemasan. ketakutan, rasa bersalah, depresi, dan kemarahan dalam urutan atau cara apa pun hingga perasaan itu hilang.

Blaska (1998) juga menguatkan pandangan bahwa keberdukaan terjadi dalam bentuk sebuah siklus, yang digambarkan sebagai berulangnya kembali satu atau lebih emosi yang merupakan bagian dari proses berduka yang dialami oleh orang tua yang memiliki anak-anak disabilitas. Hasil wawancara menemukan bahwa orang tua ingat dengan jelas bagaimana perasaan mereka ketika mereka diberi tahu bahwa anak mereka teridentifikasi disabilitas. Emosi yang mereka rasakan termasuk kekecewaan, kesedihan atau depresi, kesendirian, takut, marah, frustrasi, syok, kehancuran, mati rasa, ketidakpastian, dan merasa terjebak dan bersalah pada anak. Ibu maupun ayah melaporkan bahwa emosi ini atau yang serupa terjadi kembali secara berselang selama masa hidup anak mereka. Peristiwa tertentuu dapat memicu kembalinya perasaan-perasaan tersebut setelah padam sesaat. Peristiwa yang memicu kesedihan meliputi masalah kesehatan atau perilaku, perbandingan perkembangan atau usia dengan anak lain, masalah dan hubungan keluarga, orang tua lanjut usia dan masalah pensiun, tuntutan perawatan yang tidak biasa, masalah profesional dan terprogram, kurangnya pemahaman dan kepekaan masyarakat, dan peristiwa lain yang tampaknya tidak signifikan.

Mengkomunikasikan potensi ABK tidak mudah bagi guru. Ketidakpercayaan orang tua akan potensi ABK mereka adalah penyebabnya. Kepercayaan orang tua ini disebabkan oleh paparan stigma masyarakat tentang ABK yang serba kekurangan dan tidak mampu melakukan banyak hal. Dari kegiatan ini memunculkan lesson learned bahwa sekolah lewat guru bisa memainkan peran penting untuk membuat orang tua mengadaptasi kondisi keluarga yang 'tiba-tiba' mempunyai ABK. Orang tua di dioptimalkan dalam hal penetimaan, kesabaran dan kebersyukuran sampai pada sisi spiritual.

\section{KESIMPULAN}

Penerapan multiple intelligences dan membangun komunikasi positif atau konseling dibutuhkan untuk menyediakan pembelajaran yang lebih baik bagi anak ABK. Multiple intelligences membantu pendidikan khusus menjadi berimbang, tidak hanya didasarkan pada disabilitas anak namun juga pada sisi kelebihan anak yang tercermin dari kecerdasan majemuk. Mengkomunikasikan kecerdasan majemuk anak dapat menjadi umpan baik untuk membangun komunikasi pada orangtua dengan sikap kurang positif terhadap perkembangan anak di sekolah. Namun umpan yang baik tidak cukup untuk membangun komunikasi pada orangtua, pendidik juga perlu memahami siklus keberdukaan yang dialami orangtua dengan anak ABK. Pemahaman terhadap siklus keberdukaan dan kondisi psikis orangtua, membantu pendidik untuk memberi dukungan sosial pada orangtua agar dapat bekerjasama secara aktif dalam perkembangan anak ABK di sekolah. 


\section{REKOMENDASI}

Instrumen multiple intelligences dalam asesmen anak ABK masih memerlukan standarisasi. Namun penerapan konsep kecerdasan majemuk dalam penyelenggaraan pendidikan khsusus dibutuhkan untuk meningkatkan kualitas pendidikan luar biasa bagi anak ABK. Selain itu asesmen multiple intelligences dapat dijadikan dasar untuk memaksimalkan sarana dan program pendidikan SLB yang diatur dalam peraturan Menteri Pendidikan Nasional Republik Indonesia nomor 33 tahun 2008 tentang standar sarana dan prasarana untuk sekolah luar biasa [18]. Sebagai contoh ruang perpustakaan dapat digunakan mengembangkan kecerdasan lingustik anak, ruang orientasi dan mobilitas (OM) bisa digunakan untuk mengasah kecerdasan kinestetik-tubuh, ruang bina persepsi bunyi dan irama dapat digunakan untuk melatih kecerdasan musik, dan ruang bina pribadi dan sosial dapat digunakan untuk melatih kecerdasan interpersonal anak.

Komunikasi sekolah dan orangtua yang kurang koperatif dapat dibangun dengan menunjukkan kepedulian sekolah terhadap kondisi psikis orangtua melalui konseling dan komunikasi positif yang intensif. Memahami kedukaan orangtua dengan anak ABK dapat membantu pendidik untuk mengarahkan orangtua agar terbuka dan berkontribusi aktif terhadap pembelajaran siswa di sekolah. Namun keterampilan ini sulit dikuasai para pendidik tanpa pendampingan ahli seperti tenaga psikologi. Maka diharapkan para ahli psikologi memberi perhatian lebih terhadap kebutuhan pendidik untuk mampu berkomunikasi dengan efektif dan melakukan konseling terhadap orangtua.

\section{DAFTAR PUSTAKA}

[1] Menteri Pendidikan Nasional Republik Indonesia, Peraturan menteri pendidikan nasional republik indonesia. 2009, pp. 1-6.

[2] Sekretariat Jenderal Pusat Data dan Statistik Pendidikan dan Kebudayaan, "Statistik sekolah luar biasa (SLB)," Jakarta, 2016.

[3] L. G. Rile, M. Jade, C.- Opulencia, N. M. Decenorio, and L. Tan, "Multiple Intelligences of Students with Learning Disabilities : Its Implication for Business Curriculum Development in United Arab Emirates," Procedia Econ. Financ., vol. 23, no. October 2014, pp. 894-898, 2015.

[4] S. H. Al-onizat, "Measurement of multiple intelligences among sample of students with autism, and intellectual disability using teacher estimation and its relationship with the variables : the type and severity of disability, gender, age, type of center," Int. J. Educ., vol. 8, no. 1, pp. 107-128, 2016.

[5] S. S. Hussen, "Effect of using the activities of multiple intelligences to learn some basic skills in kata and level of harmonic behavior of the mentally handicapped: Acceptors for learning," Procedia - Soc. Behav. Sci., vol. 5, pp. 1950-1955, 2010.

[6] J. Takahashi, "Multiple intelligence theory can help promote inclusive education for children with intellectual disabilities and developmental disorders: Historical reviews of intelligence theory, measurement methods, and suggestions for inclusive education," Creat. Educ., vol. 4, no. 9, pp. 605-610, 2013.

[7] R. Hassall, J. Rose, and J. Mcdonald, "Parenting stress in mothers of children with an intellectual disability: The effects of parental cognition in relation to child characteristics and family," J. Intellect. Disabil. Res., vol. 49, no. 6 , pp. 405-418, 2005.

[8] A. F. Raya, R. Ruiz-olivares, J. Pino, and J. Herruzo, "Parenting style and parenting practices in disabled children and its relationship with academic competence and behaviour problems," Procedia - Soc. Behav. Sci., vol. 89, pp. 702-709, 2013.

[9] I. Kandel and J. Merrick, "The birth of a child with disability: Coping by parents and siblings," Sci. World J., vol. 3, pp. 741-750, 2003.

[10] E. Sen and S. Yurtsever, "Difficulties experienced by families with disabled children," JSPN, vol. 12, no. 4, pp. 238-252, 2007.

[11] J. A. Ray, J. Pewitt-Kinder, and S. George, "Partnering with families of children with special needs," Young Children, no. September, pp. 16-22, 2009.

[12] K. W. Allred, "Engaging parents of students with disabilities: Moving beyond the grief model," Improv. Sch., vol. March, pp. 1-6, 2014.

[13] K. Moses, "The impact of childhood disability: The parent's struggle," in PENT Forum, 2004, pp. 1-6.

[14] J. K. Blaska, "Cyclical grieving: Reocurring emotions experienced by parents who have children with disabilities.” Educational Resources Information Center, pp. 1-19, 1998.

[15] Menteri Pendidikan Nasional Republik Indonesia, Peraturan menteri pendidikan nasional republik indonesia. Indonesia, 2008, pp. 1-35. 